\title{
Microstructure and Shape Memory Effect of Cu-Zn-Ni Shape Memory Alloys
}

\author{
Sathish S1, U. S. Mallik², T. N. Raju1 \\ ${ }^{1}$ Department of Mechanical Engineering, Dr. Ambedkar Institute of Technology, Bangalore, India \\ ${ }^{2}$ Department of Mechanical Engineering, Siddaganga Institute of Technology, Tumkur, India \\ Email: ssiitm@yahoo.co.in
}

Received 12 December 2013; revised 7 January 2014; accepted 26 January 2014

Copyright (C) 2014 by authors and Scientific Research Publishing Inc.

This work is licensed under the Creative Commons Attribution International License (CC BY). http://creativecommons.org/licenses/by/4.0/

(c) (i) Open Access

\begin{abstract}
The microstructure, martensitic transformation behavior and shape memory effect of $\mathrm{Cu}-\mathrm{Zn}$ - $\mathrm{Ni}$ shape memory alloy have been studied by X-ray diffraction (XRD), optical microscopy (OM) and differential scanning calorimetry (DSC). The results show that the recrystallization occurs in the hot-rolled $\mathrm{Cu}-\mathrm{Zn}-\mathrm{Ni}$ alloy by annealing at $8^{\circ} 0^{\circ} \mathrm{C}$ and alloy is primarily composed of martensite. A reverse martensite transformation temperature higher than $100^{\circ} \mathrm{C}$ upon heating has been detected. The alloys exhibit good ductility and shape memory effect (SME). The results obtained are discussed in detail.
\end{abstract}

\section{Keywords}

Cu-Zn-Ni Shape Memory Alloy; Transformation Temperature; X-Ray Diffraction; Optical Microscopy; Shape Memory Effect

\section{Introduction}

A shape memory alloy (SMA) is an alloy that remembers its original shape returning the pre-deformed shape upon heating. This material is a lightweight, solid-state alternative to conventional actuators such as hydraulic, pneumatic, and motor-based systems. Shape memory alloys find applications in industries such as medical, robotics and aerospace. Shape memory alloys (SMAs) are metallic materials, which exhibit two unique properties namely, shape memory effect and super-elasticity.

Among many alloy systems which exhibit shape memory effect (SME), Cu-Al-Ni and Cu-Zn-Al shape memory alloys (SMAs) have been studied extensively over the years [1]. Most of the copper-based shape memory alloys are easy to fabricate, process and are less expensive when compared to $\mathrm{Ni}$-Ti shape memory alloys. However, $\mathrm{Cu}-\mathrm{Al}-\mathrm{Ni}$ and $\mathrm{Cu}-\mathrm{Zn}-\mathrm{Al}$ shape memory alloys in the polycrystalline state are brittle and therefore 
cannot be easily worked due to the high degree of order and high elastic anisotropy of the parent $\beta$-phase (austenitic) [2].

Cu-based shape memory alloys are currently derived from three binary alloy systems i.e., $\mathrm{Cu}-\mathrm{Zn}, \mathrm{Cu}-\mathrm{Al}$ and $\mathrm{Cu}-\mathrm{Sn}$ [3]. Among these martensitic transformations, In $\mathrm{Cu}-\mathrm{Sn}$ alloys are not perfectly thermo elastic and suffer from a rapid degradation of a shape memory properties during ageing at even moderate temperatures. It is also very brittle and the existence of $\beta$-composition range is very narrow. These alloys are therefore of theoretical interest than potential commercial shape memory alloys.

$\mathrm{Cu}-\mathrm{Zn}$ based alloys containing $\mathrm{Al}, \mathrm{Si}, \mathrm{Sn}, \mathrm{Ga}$, or $\mathrm{Mn}$ as ternary alloy and $\mathrm{Cu}-\mathrm{Al}$ based ternary alloys with alloying elements such as $\mathrm{Ni}, \mathrm{Be}, \mathrm{Zn}$ and $\mathrm{Mn}$ [4] [5] have been explored for their potential use. Currently Cu-Zn$\mathrm{Al}$ and $\mathrm{Cu}-\mathrm{Al}-\mathrm{Ni}$ shape memory alloys are commercially available and put to use in many practical applications. The alloys can also be suitably modified to meet specific requirements for practical applications by selectively alloying with suitable quaternary and grain-refining additions [6]. Accordingly quaternary alloyed SMAs such as $\mathrm{Cu}-\mathrm{Zn}-\mathrm{Al}-\mathrm{Ni}$, Cu-Zn-Al-Ni-Mn and $\mathrm{Cu}-\mathrm{Zn}-\mathrm{Ni}-\mathrm{Ti}-\mathrm{Mn}$ etc. are developed and put to use in many commercial applications. The alloys are also alloyed with grain refiners such as B, Co, Fe, Ti, V and $\mathrm{Zr}$ to reduce the size of grains and improve their mechanical properties [7].

The practical applications of a shape memory alloy depend on its characteristic transformation temperatures and the extent of shape memory effect and superelasticity. Since the shape memory properties of SMAs are sensitive to the composition of the alloy, they play a vital role in determining their transformation temperatures and shape memory characteristics [8]. The main objective of present study is to determine the influence of alloying elements zinc and nickel on the transformation temperatures, morphology of martensite formed, strain recovery by shape memory effect in a broad range of concentrations of $\mathrm{Cu}-\mathrm{Zn}-\mathrm{Ni}$ alloys.

\section{Experimental Procedure}

From phase diagram [9] pure copper, zinc and nickel were taken in right quantities [Figure 1(a)] to weigh $500 \mathrm{~g}$ of the alloy in total and were melted together in an induction furnace under an inert gas atmosphere [10]. The molten alloy was poured into a cast iron mould of dimensions $150 \mathrm{~mm} \times 100 \mathrm{~mm} \times 3 \mathrm{~mm}$ and allowed to solidify. The ingots were then homogenized at $800^{\circ} \mathrm{C}$ in the $\beta$-phase for $6 \mathrm{~h}$ under an argon atmosphere. The chemical compositions of the alloys were determined using a Perkin-Elmer inductively coupled plasma-optical emission spectrophotometer (ICP-OES), which has the capability to analyze compositions up to an accuracy level of second decimal place [9].

The homogenized alloy samples were hot rolled at $800^{\circ} \mathrm{C}$ according to phase liquidous diagram from Figure $1(\mathrm{~b})$ to a thickness of $1 \mathrm{~mm}$. The hot rolled samples were homogenized for $5 \mathrm{~h}$ at $800^{\circ} \mathrm{C}$ and step quenched into a boiling water bath $\left(\sim 100^{\circ} \mathrm{C}\right)$, followed by quenching them into a water bath at room temperature $\left(\sim 30^{\circ} \mathrm{C}\right)$. Step quenching was used to prevent the quench cracks and the pinning of martensitic plates by excess dislocations retained on quenching from high temperature [11] [12]. The shape memory effect is a temperature-dependent effect. During shape memory effect, if the recovery of shape is constrained/hindered, then the alloy generates a force that can be used to do some useful work. The transformation from austenite to martensite and the reverse transformation from martensite to austenite are diffusionless in character and occur over a temperature range. The alloys exhibit four inherent temperatures, which indicate the beginning and end of austenite and martensite transformations. These are known as characteristic transformation temperatures. These temperatures are: $M_{f}$-martensite finish; $M_{s}$-martensite start; $A_{s}$-austenite start; and $A_{f}$-austenite finish.

The microstructure and morphology of martensites formed were studied using an optical microscope. The transformation temperatures were determined using a differential scanning calorimeter (DSC) by adopting a heating and cooling rate of $10^{\circ} \mathrm{C} / \mathrm{min}$. The polycrystalline samples were analyzed by X-ray diffractometer to identify the phases formed at room temperature. The strain recovery by SME of the alloys were determined by bend test on $1 \mathrm{~mm}$ thick specimens by measuring the initial and final bend angles just before heating i.e. in the martensitic phase, and immediately after heating, i.e. in the austenitic phase of the alloys [13].

The specimens for microstructural study were prepared by following the standard metallographic practice. The polished specimens were then etched using $\mathrm{K}_{2} \mathrm{Cr}_{2} \mathrm{O}_{7}\left(2 \mathrm{~g}-\mathrm{K}_{2} \mathrm{Cr}_{2} \mathrm{O}_{7}, 8 \mathrm{ml}-\mathrm{H}_{2} \mathrm{SO}_{4}, 4\right.$ drops-HCl, $100 \mathrm{ml}$ Water) etchant. The etched samples were thoroughly cleaned with acetone and the microstructural examination was carried out using optical microscope to study the morphology and the type of martensite formed. 


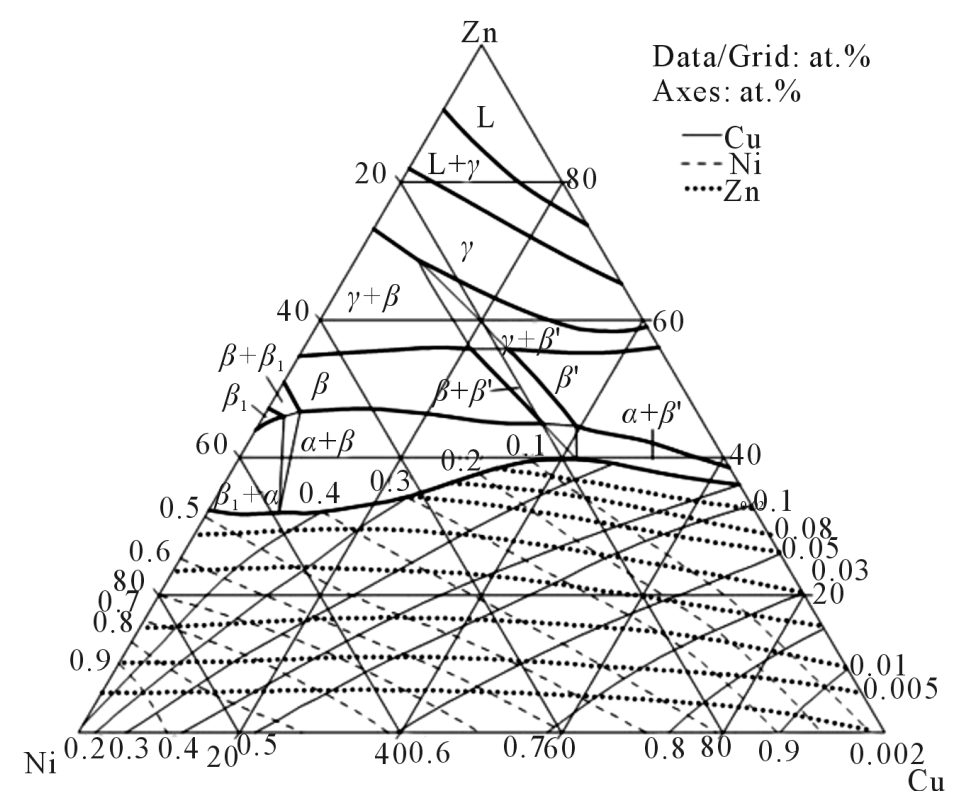

(a)

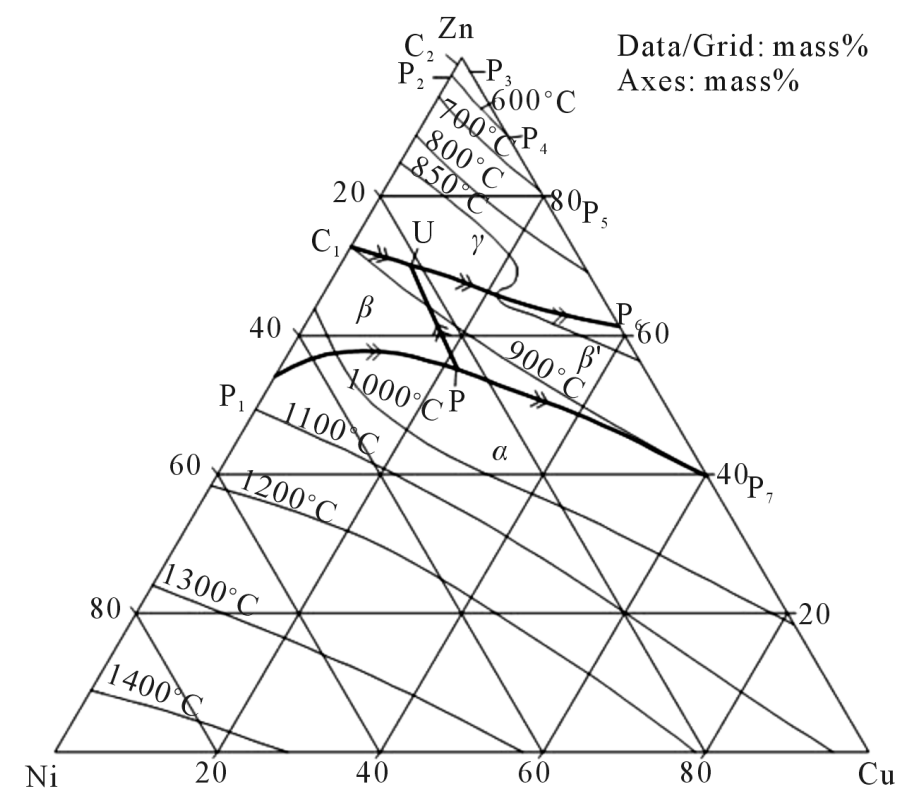

(b)

Figure 1. (a) Isothermal section of $\mathrm{Cu}-\mathrm{Zn}-\mathrm{Ni}$ at $775^{\circ} \mathrm{C}$; and (b) Liquidous projections (9).

\section{Results and Discussion}

\subsection{Chemical Composition, Transformation Temperatures and Microstructures of Ternary Cu-Zn-Ni SMAs}

The chemical compositions of the alloys, and the corresponding transformation temperatures, are given in Tables 1 and 2. Table 1 shows the chemical composition and transformation temperatures of the alloys which have almost the same $\mathrm{Cu} / \mathrm{Ni}$ ratio and varying $\mathrm{Zn}$ contents. Table 2 shows the chemical composition and transformation temperatures of the alloys which have almost a constant $\mathrm{Cu} / \mathrm{Zn}$ ratio and varying Ni contents. During heating martensite transforms to austenite and there is absorption of heat, which is marked by an endothermic 
Table 1. Chemical compositions and transformation temperatures of the alloys with almost a constant $\mathrm{Cu} / \mathrm{Ni}$ ratio and varying $\mathrm{Zn}$ contents.

\begin{tabular}{ccccccccc}
\hline \multirow{2}{*}{ Alloy ID } & \multicolumn{3}{c}{ Chemical Composition (wt. \%) } & \multicolumn{4}{c}{ Transformation Temperatures $\left({ }^{\circ} \mathrm{C}\right)$} \\
\cline { 2 - 8 } & $\mathrm{Cu}$ & $\mathrm{Zn}$ & $\mathrm{Ni}$ & $\mathrm{M}_{\mathrm{f}}$ & $\mathrm{M}_{\mathrm{s}}$ & $\mathrm{A}_{\mathrm{s}}$ & $\mathrm{A}_{\mathrm{f}}$ \\
\hline 1 & 49.27 & 45.26 & 5.47 & 74 & 90 & 95 & 138 \\
2 & 48.50 & 45.59 & 5.82 & 82 & 106 & 105 & 145 \\
3 & 48.22 & 45.63 & 6.15 & 88 & 112 & 116 & 152 \\
4 & 47.67 & 46.12 & 6.21 & 108 & 115 & 118 & 143 \\
\hline
\end{tabular}

Table 2. Chemical compositions and transformation temperatures of the alloys with almost a constant $\mathrm{Cu} / \mathrm{Zn}$ ratio and varying Ni contents.

\begin{tabular}{ccccccccc}
\hline \multirow{2}{*}{ Alloy ID } & \multicolumn{3}{c}{ Chemical Composition (wt\%) } & \multicolumn{5}{c}{ Transformation Temperatures $\left({ }^{\circ} \mathrm{C}\right)$} \\
\cline { 2 - 8 } & $\mathrm{Cu}$ & $\mathrm{Zn}$ & $\mathrm{Ni}$ & $\mathrm{M}_{\mathrm{f}}$ & $\mathrm{M}_{\mathrm{s}}$ & $\mathrm{A}_{\mathrm{s}}$ & $\mathrm{A}_{\mathrm{f}}$ \\
\hline 5 & 48.96 & 48.04 & 2.96 & 86 & 111 & 101 & 126 \\
6 & 49.24 & 46.86 & 3.75 & 72 & 121 & 116 & 143 \\
7 & 49.27 & 45.91 & 4.47 & 66 & 132 & 126 & 156 \\
8 & 48.50 & 45.59 & 5.82 & 41 & 143 & 143 & 176 \\
\hline
\end{tabular}

peak. On cooling, austenite transforms back to martensite, and heat is released, which is marked by an exothermic peak. The transformation temperature varies with the variation in zinc and nickle contents.

From Table 1 it can be observed that as the concentration of zinc increases the transformation temperatures decreases whereas Table 2 it can be observed when the concentration of nickel increases there is increase in the transformation temperatures [14]. From Table 1 and 2, it can also be observed that the martensitic start $\left(\mathrm{M}_{\mathrm{s}}\right)$ below which the alloy will be completely martensitic and austenitic finish temperature $\left(A_{f}\right)$, above which the alloy is completely austenitic varies depending on the composition of alloys. Therefore these alloys can be suitably designed for use in different temperature and also for low temperature applications [15].

Figure 2 shows the X-ray diffraction patterns of the step quenched alloys. It can be observed from Figure 2 that there is complete transformation of austenite to martensite when the alloys are step quenched from $800^{\circ} \mathrm{C}$ to $100^{\circ} \mathrm{C}$ followed by quenching to room temperature. Depending on the amount of martensite formed the intensities of the peaks corresponding to $\beta_{1}^{1}$ varies. The amount of martensite formed in turn have a detrimental effect on the shape memory characteristics of the alloys i.e. SME. In all the alloys $\beta_{1}^{1}$ martensite is predominantly formed. It can also be observed that the alloys with lower Zinc content shows formation of $\beta_{1}^{1}$ martensite predominantly [Figure 2(a)]. In alloys which have higher contents of Zinc shows formation of $\gamma_{1}^{1}$ martensite. Invariably in all the alloys there is mixture of both types of martensites.

The optical micrographs of the step quenched alloys are shown in Figure 3. The optical micrograph, Figure 3(a), of the alloy shows the presence of austenite in the as-cast alloy. From Figure 3(b) it can be observed that the alloy with lower zinc content shows formation of lath type $\beta_{1}^{1}$ martensite with a thin plate like morphology, indicating the complete transformation of austenite to martensite. Figures 3(c) and (d) also show the optical micrographs of the $\mathrm{Cu}-\mathrm{Zn}-\mathrm{Ni}$ alloy samples with higher zinc content, where formation of both kinds of martensites i.e. $\beta_{1}^{1}$ martensite and $\gamma_{1}^{1}$ martensite are formed. The $\gamma_{1}^{1}$ martensite morphology is different from that of $\beta_{1}^{1}$ martensite. The $\gamma_{1}^{1}$ martensite appears as a spear and also a thick plate-like morphology. In all the alloys it can be observed that there is a complete transformation of the parent austenitic phase to martensite. The different martensitic phases formed in the polycrystalline samples of the step quenched alloys were analyzed using $\mathrm{X}$-ray diffractometers with $\mathrm{Cu}-\mathrm{K} \alpha$ radiation, at room temperature.

\subsection{Shape Memory Effect (SME)}

The alloys were tested for its shape memory effect by using a semi empirical bend test as shown in Figure 4 [6]. The sheet specimens were bent to a U-shape in its martensitic phase by applying an initial strain of $2 \%$ around a 


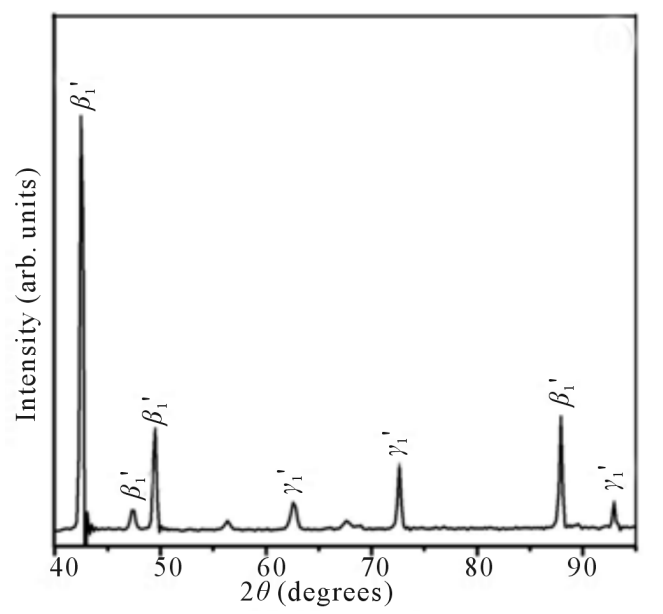

(a)

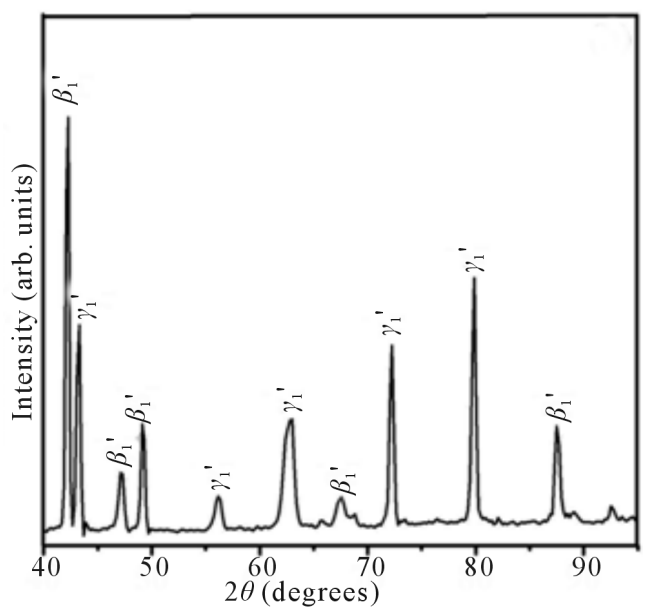

(b)

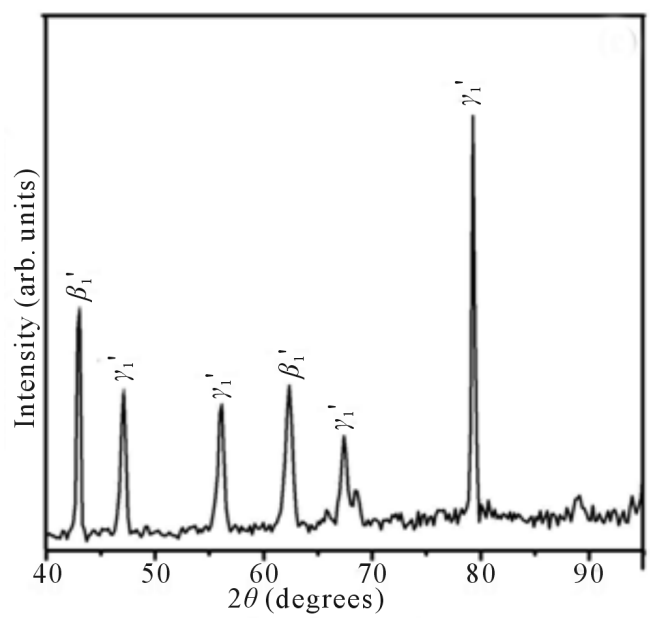

(c)

Figure 2. X-ray diffraction patterns of Cu-Zn-Ni SMAs. (a) Alloy 2; (b) Alloy 4; and (c) Alloy 5.

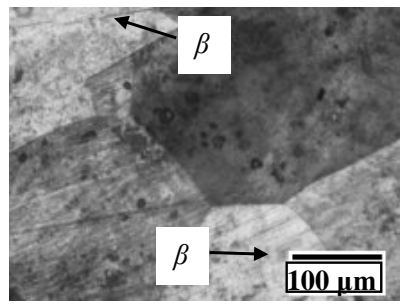

(a)

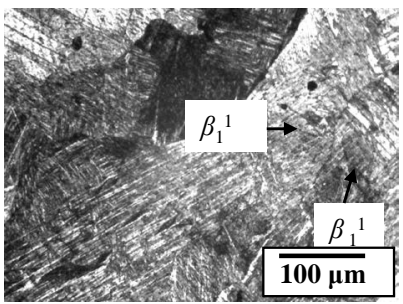

(b)

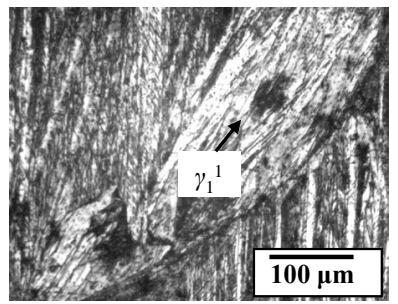

(c)

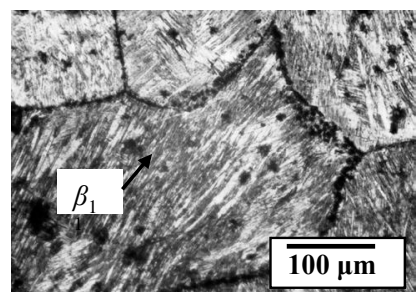

(d)

Figure 3. Optical micrographs of Cu-Zn-Ni SMAs exhibiting lath type and spear type martensite structure obtained on step quenching. (a) Alloy 2; (b) Alloy 4; (c) Alloy 5; and (d) Alloy 7. 


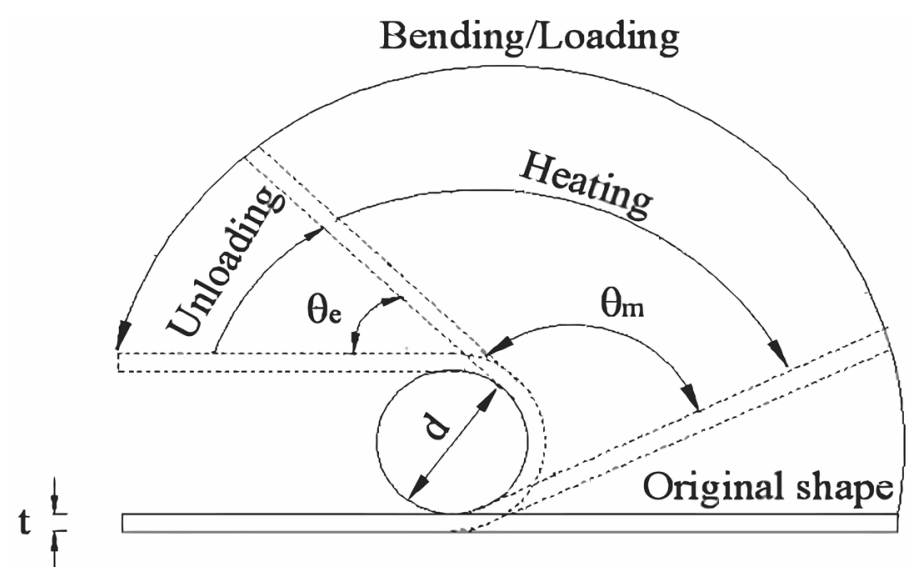

Figure 4. Schematic diagram of the bend test to determine strain recovery by SME.

round bar of diameter $50 \mathrm{~mm}$. The alloys were then heated to above their austenitic finish temperature. The corresponding angles of bend before heating and after heating to above their austenitic finish temperature were measured. The percentage of strain recovery by shape memory effect was determined by using the relation:

$$
\begin{gathered}
S M E=\frac{\theta_{m}}{180-\theta_{e}} ; \\
\varepsilon=\frac{t}{d}
\end{gathered}
$$

where $\theta_{e}=$ angle recovered on unloading, $\theta_{m}=$ angle recovered on heating, $d=50 \mathrm{~mm}, t=1 \mathrm{~mm}$ and $\varepsilon=2 \%$.

In the martensitic phase of the alloys at $\mathrm{T}<$ Martensite finish $\left(\mathrm{M}_{\mathrm{f}}\right)$. The alloys were then heated to above their Austenite finish $\left(\mathrm{A}_{\mathrm{f}}\right)$ temperature. The corresponding angles of bend before heating and after heating to above $\mathrm{A}_{\mathrm{f}}$ temperature were measured and the percentage of strain recovery was determined. These alloy system exhibit significant strain recovery by SME to the extent of $70 \%$ to $99 \%$ as shown in Table 3 . The amount of shape memory depends mainly on the amount of martensite present in the alloy and the extent of transformation of martensite to austenite.

If there is any residual martensite remaining in the austenite phase of the alloy the strain recovery will be reduced proportionately [16]. The other factors which influence the strain recovery by SME are the imperfections in the material, such as quenched in vacancies, dislocations, etc., which cause the pinning of martensitic plates, thereby hampering the transformation and in turn the strain recovery. These can be reasonably avoided by step quenching. But it has been observed, that the alloys with the higher concentration of Zinc and lesser concentration of nickel exhibit higher recovery strain by SME. It may be attributed to the ease with which the martensitic to austenitic transformation occurs, and the formation of a higher proportion $\gamma_{1}^{\prime}$ martensite compared with that of $\beta_{1}{ }^{\prime}$ martensite in the alloys. This also leads to decrease in the transformation temperatures.

\section{Conclusions}

1) The type and amount of martensite formed in these alloys are mainly dependent upon the amount of Zinc and Nickel in the alloys. $\beta_{1}{ }^{\prime}$ martensitic phase is predominant in the composition range of the alloys chosen. Two kinds of martensites are observed in these alloys i.e. $\beta_{1}^{1}$ martensite and $\gamma_{1}^{\prime}$ martensite with high density of twins. The $\beta_{1}^{1}$ martensite is formed when the content of zinc is less and $\gamma_{1}^{\prime}$ martensite is formed when the content of zinc is more in the composition range of the studied alloys.

2) The transformation temperatures are highly sensitive to the variation in zinc concentrations of the alloy. As the content of zinc increases, the transformation temperatures decrease, whereas as the content of nickel increases, the transformation temperatures increase.

3) The alloys exhibit good strain recovery by $S M E$. A strain recovery of up to $99 \%$ by $S M E$ was observed inthese alloys. The variation in zinc and nickel in the alloys concentration does not significantly affect the strain 
Table 3. Strain recovery by SME of Cu-Zn-Ni SMAs.

\begin{tabular}{ccccc}
\hline \multirow{2}{*}{ Alloy ID } & \multicolumn{2}{c}{ Composition (wt\%) } & Strain Recovery (\%) \\
\cline { 2 - 4 } 2 & $\mathrm{Cu}$ & $\mathrm{Zn}$ & $\mathrm{Ni}$ & 70 \\
4 & 48.50 & 45.59 & 5.82 & 85 \\
5 & 47.67 & 46.12 & 6.21 & 99 \\
7 & 48.96 & 48.04 & 2.96 & 87 \\
\hline
\end{tabular}

recovery by SME but depends on the amount and type of martensite transformed.

\section{References}

[1] Duerig, T.W., Melton, K.N., Stockel, D. and Wayman, C.M. (1990) Engineering Aspects of Shape Memory Alloys. Butterworth Heinemann Publishing, London, 3-20.

[2] Sutou, Y., Omori, T., Kainuma, R., Ono, N. and Ishida, K. (2002) Enhancement of Superelasticity in Cu-Al-Mn-Ni Shape Memory Alloys by Texture Control. Metallurgical and Materials Transactions A, 33A, 2817-2824.

[3] Ahlers, M. (2008) The Martensitic Transformation in the Cu-Zn Based Shape Memory Alloys as a Tool for the Evaluation of Transformation Mechanisms and Phase Stabilities. Materials Science and Engineering A, 481-482, 500-503. http://dx.doi.org/10.1016/j.msea.2007.02.136

[4] Kainuma, R., Takahashi, S. and Ishida, K. (1996) Thermoelastic Martensite and Shape Memory Effect in Ductile Cu-Al-Mn Alloys. Metallurgical and Materials Transactions A, 27A, 2187-2195.

[5] Kainuma, R., Satoh, N., Liu, X.J., Ohnuma, I. and Ishida, K. (1998) Phase Equilibria and Heusler Phase Stability in Cu-Rich Portion of the Cu-Al-Mn System. Journal of Alloys and Compounds, 266, 191-200. http://dx.doi.org/10.1016/S0925-8388(97)00425-8

[6] Mallik U.S. and Sampath, V. (2008) Influence of Aluminum and Manganese Concentration on the Shape Memory Characteristics of Cu-Al-Mn Shape Memory Alloys. Journal of Alloys and Compounds, 459, 142-147. http://dx.doi.org/10.1016/j.jallcom.2007.04.254

[7] Mallik, U.S. and Sampath, V. (2008) Effect of Composition and Ageing on Damping Characteristics of Cu-Al-Mn Shape Memory Alloys. Materials Science and Engineering A, 478, 48-55. http://dx.doi.org/10.1016/j.msea.2007.05.073

[8] Sutou, Y., Kainuma, R. and Ishida, K. (1999) Effect of Alloying Elements on the Shape Memory Properties of Ductile Cu-Al-Mn Alloys. Materials Science and Engineering A, 273, 375-379. http://dx.doi.org/10.1016/S0921-5093(99)00301-9

[9] ASM (1992) ASM Handbook Volume 03: Alloy Phase Diagrams. 10th Edition, ASM International, Almere.

[10] Mallik, U.S. and Sampath, V. (2006) Influence of Composition on Shape Memory Characteristics of Cu-Al-Mn Shape Memory Alloys. Proceedings of International Conference on Advances in Materials and Materials Processing (ICAMMP-2006), Kharagpur, 3-5 February 2006, 583-588.

[11] Lopez del Castillo, C., Blazquez, M.L., Gomez, C., Mellor, B.G., de Diego, N. and del Rio, J. (1988) The Stabilization of Martensite in Cu-Al-Mn Alloys. Journal of Materials Science, 23, 3379-3382. http://dx.doi.org/10.1007/BF00551322

[12] Husain, S.W. and Clapp, P.C. (1988) The Intergranular Embrittlement of Cu-Al-Ni $\beta$-Phase Alloys. Journal of Materials Science, 22, 2351-2356. http://dx.doi.org/10.1007/BF01082115

[13] Kim, H.W. (2004) A Study of the Two-Way Shape Memory Effect in Cu-Zn-Al Alloys by the Thermomechanical Cycling Method. Journal of Materials Processing Technology, 146, 326-329. http://dx.doi.org/10.1016/j.jmatprotec.2003.11.018

[14] Sarı, T.K. (2008) Effects of Deformation on Microstructure and Mechanical Properties of a Cu-Al-Ni Shape Memory Alloy. Material Characterizations, 59, 920-929. http://dx.doi.org/10.1016/j.matchar.2007.07.017

[15] Shi, D., Gui, J., Tan, S.S. and Wang, R. (1998) Effect of Ageing in the Two-Phase Region in a Cu-Zn-Al Shape Memory Alloy. Materials Science and Engineering B, 56, 31-36. http://dx.doi.org/10.1016/S0921-5107(98)00179-2

[16] Morris, M.A. and Lipe, T. (1994) Microstructural Influence of Mn Additions on Thermoelastic and Pseudoelastic Properties of Cu-Al-Ni Alloys. Acta Metallurgica et Materialia, 42, 1583-1594.

http://dx.doi.org/10.1016/0956-7151(94)90368-9 